\title{
Níveis de irrigação e doses de potássio sobre os teores foliares de nutrientes do maracujazeiro amarelo
}

\author{
Valdemício F. de Sousa ${ }^{1}$, Marcus V. Foleggatti², José A. Frizzone ${ }^{2}$, Thiago J. Dias ${ }^{3}$, Boanerges S. Albuquerque Júnior ${ }^{4}$ \& Erasmo C. Batista ${ }^{5}$
}

\section{RESUMO}

Este trabalho foi realizado com o objetivo de avaliar o efeito de níveis de irrigação e doses de potássio aplicadas via água de irrigação por gotejamento, sobre os teores foliares de nutrientes do maracujazeiro amarelo. $\mathrm{O}$ trabalho foi desenvolvido no Campo Experimental da Fazenda Areão, da ESALQ/USP, em Piracicaba, SP ( $22^{\circ} 42^{\prime} 30^{\prime \prime}$ S e 47 $38^{\prime} 00^{\prime \prime}$ W); utilizou-se, com tal propósito, um delineamento experimental de blocos ao acaso com quatro repetições, cujos tratamentos foram arranjados no esquema de parcelas subdivididas e resultaram da combinação de quatro níveis de irrigação $\left(\mathrm{L}_{1}=0,25 \mathrm{~L}\right.$; $L_{2}=0,50 L ; L_{3}=0,75 L ; L_{4}=1,00 \mathrm{~L}$ ) em que $L$ é o volume de água médio medido em lisímetros, e cinco níveis de potássio $\left(\mathrm{K}_{0}=0,000 ; \mathrm{K}_{1}=0,225 ; \mathrm{K}_{2}=0,450 ; \mathrm{K}_{3}=0,675\right.$ e $\mathrm{K}_{4}=0,900 \mathrm{~kg}_{\text {planta }}{ }^{-1} \mathrm{ano}^{-1}$ de $\left.\mathrm{K}_{2} \mathrm{O}\right)$, aplicadas via água de irrigação. Avaliou-se a concentração de nutrientes nas plantas através da diagnose foliar, realizada no período de colheita de frutos. Os teores dos nutrientes nas folhas do maracujazeiro não foram influenciados pelos níveis de irrigação nem pela interação irrigação x potássio, ao passo que a acumulação de $\mathrm{K}, \mathrm{Ca}, \mathrm{Mg}$, B e $\mathrm{Mn}$ o foram pelas doses de potássio.

Palavras-chave: fertirrigação, nutrição de planta, Passiflora edulis

\section{Effect of irrigation levels and potassium doses on nutrient content of yellow passion fruit leaves}

\begin{abstract}
The objective of this work was to evaluate the effect of irrigation and potassium levels applied through irrigation water by drip irrigation on the nutrient content of yellow passion fruit. The experiment was performed in the Experimental Field of the Areão Farm at ESALQ/USP, Piracicaba, São Paulo, Brazil ( $22^{\circ} 42^{\prime} 30^{\prime \prime}$ S e $47^{\circ} 38^{\prime} 00^{\prime \prime} \mathrm{W}$ ). An experimental design of randomized blocks in subdivided plots with four replications was used. The treatments resulted from the combination of four irrigation levels $\left(L_{1}=0.25 \mathrm{~L}, \mathrm{~L}_{2}=0.50 \mathrm{~L}, \mathrm{~L}_{3}=0.75 \mathrm{~L}\right.$ and $\left.\mathrm{L}_{4}=1.00 \mathrm{~L}\right)$, in which $\mathrm{L}$ is the average water depth measured in lysimetr, and five potassium doses $\left(\mathrm{K}_{0}=0.00 ; \mathrm{K}_{1}=0.225 ; \mathrm{K}_{2}=0.450 \mathrm{~K}_{3}=0.675\right.$ and $\mathrm{K}_{4}=0.90 \mathrm{~kg}$ plant $^{-1}$ year $^{-1}$ of $\mathrm{K}_{2} \mathrm{O}$ ), applied through irrigation water every seven days. The nutrient concentration in the plants was evaluated through leaf diagnosis, performed during the fruit harvests period. The nutrient content in passion fruit leaves was not influenced by irrigation levels and irrigation $\mathrm{X}$ potassium interaction, but the concentrations of $\mathrm{K}$, $\mathrm{Ca}, \mathrm{Mg}, \mathrm{B}$ and $\mathrm{Mn}$ were influenced by potassium doses.
\end{abstract}

Key words: fertirrigation, plant nutrition, Passiflora edulis

\footnotetext{
${ }^{1}$ Embrapa Meio-Norte, Av. Duque de Caxias, 5650, bairro Buenos Aires, CP 01, CEP 64006-220, Teresina, PI. Fone: (86) 3225-1141; fax: (86) 3225-1142. E-mail:vfsousa@cpamn.embrapa.br

2 ESALQ/USP, CEP 13418-900, Piracicaba, SP. E-mail: mvfolega@carpa.ciagri.usp.br, frizzone@carpa.ciagri.usp.br

${ }^{3}$ M.Sc. Bolsista FAPEPI/Embrapa Meio-Norte, CEP 64006-200, Teresina, PI. E-mail: tjardelino@hotmail.com

${ }^{4}$ Doutorando, UAEAg/UFCG, Rua Aprígio Veloso, 882, CEP 58109-930, Campina Grande, PB. E-mail: baojunior@clic21.com.br

${ }^{5}$ Mestrando em Irrigação e Drenagem, URFSA/DCA, CEP 59626-310, Mossoró, RN. E-mail: erasmoc.batista@bol.com.br
} 


\section{INTRODUÇÃO}

O maracujazeiro amarelo (Passiflora edulis Sims f. flavicarpa Deg) se desenvolve em diferentes tipos de solo; contudo, os arenosos e os areno-argilosos, profundos e bem drenados, são mais adequados para a cultura (Souza \& Meletti, 1997; Teixeira, 1998; Cavalcante et al., 2005).

A cultura possui ciclos alternados de vegetação e de produção, mais intensos no início da primavera estendendo-se até o final do outono, cujo comportamento requer que o pomar esteja sempre nutricionalmente equilibrado em macro e micronutrientes (Menzel et al., 1993, Quaggio \& Piza Júnior, 1998; Carvalho et al., 2001).

O monitoramento das exigências da cultura e do seu estado nutricional constitui fator de relevante importância no processo produtivo do maracujazeiro amarelo; por outro lado, os custos financeiros com adubo são elevados fazendo-se necessário otimizar cada vez mais o seu uso (Borges et al., 2002; Carvalho et al., 2002; Dias et al., 2004).

Apesar das sugestões e recomendações para adubação do maracujazeiro, observa-se que a adubação de formação do pomar ainda é feita sob diferentes formas e varia marcadamente entre autores e produtores; trata-se de cultura exigente em nutrientes razão por que se faz necessário parcelar a adubação nos diferentes estádios da cultura com a finalidade de disponibilizar os nutrientes às plantas, de acordo com suas exigências, nas distintas fases do ciclo (Rizzi et al., 1998). Autores como Meletti (1996), Souza \& Meletti (1997) e Sousa (2000) detalham mais esta recomendação através da aplicação de $10 \mathrm{~g}$ de $\mathrm{N}$ aos 30 dias do plantio; 15 g de $\mathrm{N}$, aos 60 dias; 20 g de $\mathrm{N}$ e 20 g de $\mathrm{K}_{2} \mathrm{O}$ aos 90 dias e $30 \mathrm{~g}$ de $\mathrm{K}_{2} \mathrm{O}$ aos 120 dias; para a adubação de produção, os resultados de pesquisas e recomendações são bastante divergentes na literatura.

O potássio é o elemento de maior mobilidade na planta; no entanto, sua disponibilidade é bastante influenciada pelo teor de água no solo devido, principalmente, à difusão e à relação de cátions (Raij, 1991). A falta de umidade no solo provoca a queda das folhas e dos frutos, sobretudo no início de seu desenvolvimento (Ruggiero et al., 1996).

De acordo com Baumgartner et al. (1978) e Primavesi \& Malavolta (1980), o maracujazeiro amarelo apresenta exigências nutricionais até os 262 dias após plantio, nessa ordem: $\mathrm{N}>\mathrm{K}>\mathrm{Ca}>\mathrm{S}>\mathrm{Mg}>\mathrm{P}>\mathrm{B}>\mathrm{Mn}>\mathrm{Zn}>\mathrm{Cu}$ $>\mathrm{Mo}$, sendo que apenas as deficiências de $\mathrm{N}, \mathrm{S}$, Ca e $\mathrm{Cu}$ mostraram efeito acentuado no desenvolvimento das plantas, porém é conveniente salientar que o maior aumento na absorção de N, P e Ca ocorre no período da pré-frutificação, sendo que o acúmulo de nitrogênio e de potássio é mais intenso nos frutos, estabilizando-se no período de amadurecimento (Kliemann et al., 1986).

Quanto à composição mineral do maracujazeiro amarelo, tem-se verificado, também, grande variação, como se constata nos dados apresentados por IFA (1992) e Malavolta et al. (1997); essas diferenças podem ser ocasionadas por alguns fatores, como clima, época de amostragem, variedade, manejo da cultura e da fertilidade do solo. Hoagland (1944), apud Primavesi \& Malavolta (1980), discorre que um aumen- to na absorção de cálcio ou de magnésio tende a reduzir a absorção de potássio cujo efeito antagônico também existe, embora com menor intensidade.

Este trabalho foi realizado com o objetivo de avaliar o efeito de níveis de irrigação e doses de potássio aplicados via água de irrigação por gotejamento, sobre os teores foliares de nutrientes do maracujazeiro amarelo.

\section{MATERIAL E MÉTODOS}

O experimento foi realizado no Campo Experimental da Fazenda Areão, da ESALQ-USP, localizado em Piracicaba, São Paulo, na latitude de $22^{\circ} 42^{\prime} 30^{\prime \prime}$ S e longitude de $47^{\circ} 38^{\prime} 00^{\prime}$ W. O solo da área experimental é classificado como Argissolo Vermelho Eutrófico; amostras de solo foram coletadas nas camadas de 0,00-0,20, 0,20-0,40 e 0,40-0,60 m (Tabelas 1 e 2) para caracterização física e química, adotando-se metodologia proposta pela EMBRAPA (1997). A temperatura média registrada nos meses de execução do experimento foi de $21,7^{\circ} \mathrm{C}$, com umidade relativa do ar de $76,8 \%$, sendo a precipitação pluviométrica acumulada de $1160 \mathrm{~mm}$ e a média diária da evapotranspiração de referência de 3,28 mm d$^{-1}$ (Tabela 3).

O preparo do solo consistiu de duas gradagens com aplicação de 2 t de calcário dolomítico por hectare, feita com base na análise de solo e exigências da cultura, objetivando-se elevar o índice de saturação por base para cerca de $80 \%$ (Meletti \& Maia, 1999). As covas foram abertas no espaçamento de 3,5 x 4,0 m, de formato cilíndrico, com 1,0 m de diâmetro e 0,5 m de profundidade; a adubação de fundação foi realizada segundo as recomendações apresentadas por Meletti \& Maia (1999) aplicando-se, por cova, $40 \mathrm{~L}$ de esterco de curral, $0,20 \mathrm{~kg}$ de $\mathrm{P}_{2} \mathrm{O}_{5}$ (superfosfato simples), $0,004 \mathrm{~kg}$ de $\mathrm{Zn}$ (sulfato de zinco) e $0,001 \mathrm{~kg}$ de B (ácido bórico); as mudas do maracujazeiro amarelo (Passiflora edulis (Sims) f. flavicarpa Deg) foram transplantadas com idade de 35 dias.

Tabela 1. Caracterização física do solo da área experimental: capacidade de campo (CC), ponto de murcha permanente (PMP), densidade global (ps) e teores de argila, silte e areia

\begin{tabular}{|c|c|c|c|c|c|c|}
\hline \multirow{2}{*}{$\begin{array}{c}\text { Camada } \\
\mathbf{m}\end{array}$} & CC & PMP & \multirow{2}{*}{$\underset{\mathrm{kg} \mathrm{dm}^{-3}}{\rho s}$} & Argila & Silte & Areia \\
\hline & \multicolumn{2}{|c|}{$\mathrm{cm}^{3} \mathrm{~cm}^{-3}$} & & & $\mathrm{~g} \mathrm{~kg}^{-1}$ & \\
\hline $0,0-0,2$ & 0,41 & 0,35 & 1,49 & 624,00 & 172,00 & 204,00 \\
\hline $0,2-0,4$ & 0,42 & 0,35 & 1,46 & 694,30 & 138,30 & 167,40 \\
\hline $0,4-0,6$ & 0,45 & 0,38 & 1,43 & 688,90 & 136,40 & 174,80 \\
\hline
\end{tabular}

Tabela 2. Caracterização química do solo da área experimental: $p H$, matéria orgânica (M.O), macronutrientes, capacidade de troca de cátions (T) e saturação por bases (V)

\begin{tabular}{|c|c|c|c|c|c|c|c|c|c|}
\hline \multirow{2}{*}{$\begin{array}{c}\text { Camada } \\
\mathrm{m}\end{array}$} & \multirow{2}{*}{$\underset{\mathrm{CaCl}}{\mathrm{pH}}$} & \multirow{2}{*}{$\begin{array}{l}\text { M.O. } \\
\text { g dm }\end{array}$} & $\bar{P}$ & $\bar{K}$ & $\mathrm{Ca}$ & $\mathrm{Mg}$ & $\mathrm{H}+\mathrm{Al}$ & $\bar{T}$ & V \\
\hline & & & \multicolumn{2}{|c|}{$\mathrm{mg} \mathrm{dm}{ }^{3}$} & \multicolumn{3}{|c|}{$\mathrm{mmol}_{\mathrm{c}} \mathrm{dm}^{3}$} & \multicolumn{2}{|c|}{$\%$} \\
\hline $0,0-0,2$ & 5,20 & 14 & 4 & 1,50 & 33 & 13 & 28 & 75,50 & 63 \\
\hline $0,2-0,4$ & 5,00 & 17 & 4 & 1,60 & 28 & 12 & 31 & 72,60 & 57 \\
\hline $0,4-0,6$ & 5,30 & 9 & 6 & 0,50 & 32 & 6 & 22 & 60,50 & 64 \\
\hline
\end{tabular}


Tabela 3. Valores médios da temperatura (T), umidade relativa do ar (UR), precipitação pluviométrica (P) e média diária da evapotranspiração de referência ETo) estimada pelo Método Penman-Monteith, no período de maio/1999 - abril/2000

\begin{tabular}{lccrc}
\hline Meses & $\begin{array}{c}\text { T } \\
{ }^{\circ} \mathbf{C}\end{array}$ & $\begin{array}{c}\text { UR } \\
\%\end{array}$ & $\begin{array}{c}\text { P } \\
\mathbf{~ m m ~}\end{array}$ & $\begin{array}{c}\text { ETo } \\
\mathbf{m m} \mathbf{~ d}^{-1}\end{array}$ \\
Maio & 18,30 & 79 & 51,30 & 2,06 \\
Junho & 17,50 & 83 & 68,60 & 1,76 \\
Julho & 19,20 & 77 & 2,70 & 2,11 \\
Agosto & 19,10 & 64 & 0,00 & 2,87 \\
Setembro & 21,40 & 70 & 85,90 & 3,82 \\
Outubro & 21,90 & 73 & 28,50 & 4,43 \\
Novembro & 22,60 & 72 & 52,10 & 4,01 \\
Dezembro & 24,80 & 78 & 269,90 & 4,77 \\
Janeiro & 24,70 & 83 & 235,90 & 3,77 \\
Fevereiro & 24,60 & 87 & 195,00 & 3,62 \\
Març0 & 24,10 & 84 & 170,00 & 3,20 \\
Abril & 21,90 & 72 & 0,00 & 2,91 \\
\hline
\end{tabular}

O sistema de irrigação utilizado foi o gotejamento com gotejadores “on line”, de vazões diferenciadas (2,4 e 4,0 L h-1), distribuídos em quantidade variada por planta para permitir a casualização dos níveis de irrigação por tratamento; por sua vez, os gotejadores foram dispostos em círculo, com raio médio de $0,40 \mathrm{~m}$ do caule da planta.

No período de realização do experimento a quantidade de água aplicada foi definida de acordo com o balanço médio diário de entrada e saída de água, em quatro lisímetros de drenagem contendo uma planta em cada um, considerando-se a precipitação efetiva e a eficiência do sistema de irrigação. As medições para determinação do volume de água, foram realizadas pela manhã, entre 8 e 10 h, durante todo o período de realização do experimento; já os lisímetros foram construídos nas dimensões de 1,28 e 0,70 m de diâmetro e altura, respectivamente, instalados no centro da área experimental. Para a determinação da lâmina de água equivalente ao máximo nível de irrigação, utilizaram-se as Eq. 1 e 2.

$$
\begin{gathered}
\mathrm{V}=\frac{\mathrm{n}_{\mathrm{g}} \mathrm{gTi}}{\mathrm{E}_{\mathrm{f}}} \\
\mathrm{L}=\frac{\mathrm{V}}{\mathrm{A}_{1}}
\end{gathered}
$$

em que:

V - volume de água aplicado em cada lisímetro, L

$\mathrm{n}_{\mathrm{g}}$ - número de gotejador no lisímetro

$\mathrm{q}$ - vazão do gotejador, $\mathrm{L} \mathrm{h}^{-1}$

$\mathrm{Ti}$ - tempo de irrigação, $\mathrm{h}$

$E_{\mathrm{f}}$ - eficiência de irrigação $(0,90)$

L - lâmina máxima de irrigação, mm

$\mathrm{A}_{\mathrm{l}}$ - área do lisímetro, $\mathrm{m}^{2}$

O momento da irrigação foi definido em função do potencial de água no solo na capacidade de campo (-8,0 kPa) adotando-se uma faixa de potencial entre $-8,5$ e $-10,0 \mathrm{kPa}$, medido nos tensiômetros instalados nos lisímetros, na profundidade de $0,30 \mathrm{~m}$. Fez-se o monitoramento da umidade no solo indiretamente, por intermédio de tensiômetros ins- talados a $0,30 \mathrm{~m}$ do caule da planta e nas profundidades de 0,$10 ; 0,30 ; 0,50$ e $0,70 \mathrm{~m}$.

Utilizou-se o delineamento experimental de blocos ao acaso com quatro repetições sendo os tratamentos arranjados no esquema de parcelas subdivididas e tratamentos constituídos de cinco doses de potássio (parcelas) e quatro níveis de irrigação (subparcelas); cada unidade experimental se compunha de duas plantas úteis e duas de bordadura; por outro lado, as doses de potássio aplicadas, expressas em $\mathrm{kg}$ de $\mathrm{K}_{2} \mathrm{O}$ planta $^{-1}$ ano-1 $^{-1}$ foram: $\mathrm{K}_{0}=0,000 ; \mathrm{K}_{1}=0,225 ; \mathrm{K}_{2}=0,450$; $\mathrm{K}_{3}=0,675$ e $\mathrm{K}_{4}=0,900$; como fontes de potássio, utilizamse cloreto de potássio (período de 0 a 120 dias após o transplantio das mudas - DAT) e nitrato de potássio (de 120 a 360 DAT). Os níveis de irrigação foram: $L_{1}=0,25 \mathrm{~V}(926,76 \mathrm{~L})$; $\mathrm{L}_{2}=0,50 \mathrm{~V}(1.528,20 \mathrm{~L}) ; \mathrm{L}_{3}=0,75 \mathrm{~V}(2.117,28 \mathrm{~L}) ; \mathrm{L}_{4}=1,00 \mathrm{~V}$ (2.706,36 L), em que $\mathrm{V}$ é o volume médio de água aplicado no lisímetro.

As adubações de formação e de produção com nitrogênio e os tratamentos com potássio, foram definidas com base nas recomendações apresentadas por Meletti \& Maia (1999) e feitas por meio da água de irrigação, na freqüência de aplicação de sete dias; aplicaram-se, nas fases de formação (0 a 120 DAT) e de produção (120 a 360 DAT) $0,10 \mathrm{~kg}$ de $\mathrm{N}$ e $0,38 \mathrm{~kg}$ de $\mathrm{N}$ por planta, respectivamente; no caso do potássio foram aplicados 10 e $90 \%$ das dosagens estabelecidas para cada tratamento, nas respectivas fases de formação e de produção da cultura.

Na fase de formação a distribuição dos nutrientes (N e K) ao longo do ciclo da cultura foi feita de forma linear, em quinze aplicações de quantidades iguais. Durante a fase de produção esses nutrientes foram aplicados 32 vezes, conforme a marcha de absorção de nutrientes para o maracujazeiro, adaptado de Haag et al. (1973).

Avaliou-se a concentração de nutrientes nas plantas por meio de diagnose foliar, realizada no período de colheita dos frutos, enquanto as amostras de folhas foram coletadas em ramos medianos de cada planta, em todos os blocos, retirando-se-lhes as terceira e quarta folhas dos ramos, contadas a partir do broto terminal (Malavolta et al., 1997), para posterior determinação em laboratório, dos conteúdos de macro e micronutrientes: N, P, K, Ca, Mg, S, B, Mn, Zn, Cu e Mo, conforme metodologia descrita em EMBRAPA (1997).

\section{RESULTADOS E DISCUSSÃO}

A composição nutricional foliar do maracujazeiro não foi influenciada pelos níveis de irrigação nem pela interação níveis de irrigação x doses de potássio, porém as doses de potássio exerceram efeitos significativos sobre os teores dos macronutrientes $\mathrm{K}$, Ca e Mg e dos micronutrientes B e Mn nas folhas das plantas.

Os teores de $\mathrm{K}$ nas folhas do maracujazeiro aumentaram linearmente a nível de $7,4978 \mathrm{~g} \mathrm{~kg}^{-1}$ por aumento unitário do elemento fornecido na água de irrigação (Figura 1A).

Comparativamente, os resultados são semelhantes aos obtidos por Haag et al. (1973); entretanto, em todas as dosagens, os teores foliares estiveram abaixo da faixa adequada para a 

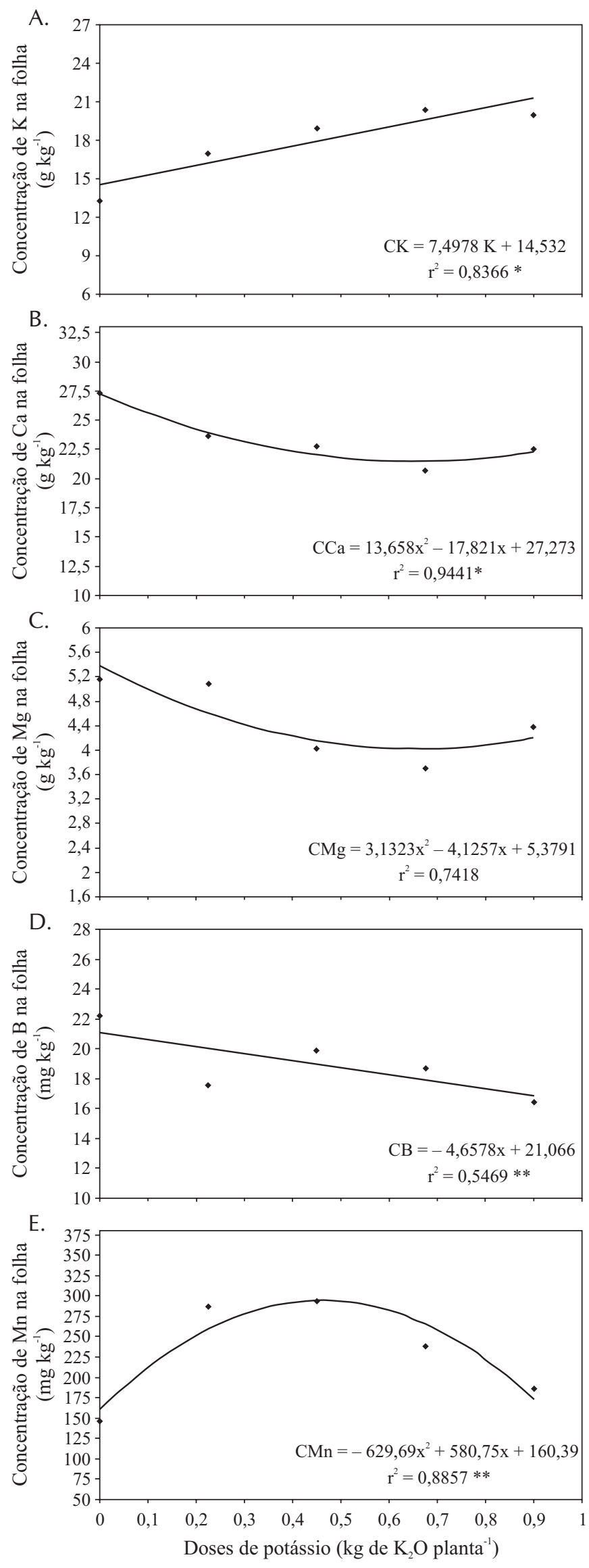

Figura 1. Teores foliares de potássio $(A)$, de cálcio $(B)$, magnésio $(C)$, boro (D) e de manganês (E) nas folhas do maracujazeiro amarelo em função de níveis de $\mathrm{K}_{2} \mathrm{O}$ aplicados ao solo, via água de irrigação cultura, ou seja, entre 26,1 e 45,1 $\mathrm{g} \mathrm{kg}^{-1}$ considerada, por Malavolta et al. (1997) e dos valores encontrados por Carvalho et al. (2002), Borges et al. (2002) e Carvalho et al. (2001), Menzel et al. (1986), Primavesi \& Malavolta (1980), Baumgartner et al. (1978), mostrando que as plantas apresentavam deficiência de potássio, cujas diferenças podem ser atribuídas à idade das plantas, época de coleta das folhas, emissão das flores, gavinhas, botões florais e desenvolvimento de frutos. Em geral, tais fatores são responsáveis pelas variações na composição mineral da cultura (Kliemann et al., 1986; Quaggio \& Piza Junior, 1998; Carvalho et al., 2001).

As amostras foram coletadas após se ter colhido em torno de $75 \%$ da safra, de uma produção relativamente grande de frutos que, provavelmente, extraiu boa parte do potássio absorvido pelas plantas considerando-se que é no período de frutificação, formação e maturação dos frutos, que as plantas mais demandam potássio, tornando-se o principal nutriente para o maracujazeiro nesta fase (Haag et al., 1973; Kliemann et al., 1986; Menzel et al., 1993; Santos, 2004; Araújo et al., 2005; Mesquita et al., 2006).

Com relação ao cálcio, constataram-se efeitos significativos $(\mathrm{P}<0,05)$ dos níveis das doses de potássio sobre os teores desse elemento nas folhas do maracujazeiro amarelo. Os maiores teores de Ca nas folhas, em torno de 29,47 $\mathrm{g} \mathrm{kg}^{-1}$, foram encontrados nos tratamentos que não receberam a dose de K. Houve tendência de redução na absorção e acumulação do cálcio pelo o maracujazeiro amarelo, com o aumento das doses de potássio aplicadas. Com o aumento das doses de $\mathrm{K}$ até $0,652 \mathrm{~kg}$ de $\mathrm{K}_{2} \mathrm{O}$ planta por ano, ocorreu queda, aumentando a partir deste até a dose de $0,90 \mathrm{~kg}$ de $\mathrm{K}_{2} \mathrm{O}$ planta $^{-1}$ ano $^{-1}$, cujo ajuste significativo $(\mathrm{P}<0,05)$ foi feito através de um polinômio de segundo grau, com coeficiente de determinação (Figura 1B).

Os teores de $\mathrm{Mg}$ nas folhas do maracujazeiro tiveram comportamento semelhante ao da concentração de Ca, com os maiores valores correspondentes aos tratamentos 0,00 e $0,225 \mathrm{~kg}$ de $\mathrm{K}_{2} \mathrm{O}$ planta por ano e posteriores reduções até a aplicação de $0,652 \mathrm{~kg}$ de $\mathrm{K}_{2} \mathrm{O}$ planta por ano, aumentando em seguida com a dose de $0,90 \mathrm{~kg}$ de $\mathrm{K}_{2} \mathrm{O}$ planta por ano (Figura 1C), tal como verificado para o cálcio, revelando efeito quadrático $(\mathrm{P}<0,05)$. Em trabalhos desenvolvidos, Carvalho et al. (2001) observaram, também, que os teores de Mg nas folhas decresceram com o aumento da quantidade de potássio aplicado via água de irrigação; conforme Prado et al. (2004) tal fato ocorreu devido, provavelmente, à competição entre os cátions $\mathrm{Mg}^{++}$e $\mathrm{K}^{+}$.

O comportamento verificado nos teores de Ca e Mg no maracujazeiro indica que maiores absorções desses elementos por esta cultura ocorrem na ausência ou com pequenas doses de K aplicadas ao solo, ou seja, há tendência sempre decrescente na absorção desses elementos com a elevação da quantidade de potássio aplicado (Primavesi \& Malavolta, 1980; Malavolta, 1981).

A literatura evidencia ainda que a absorção de cátions divalentes está diretamente associada aos teores de potássio presentes no solo, indicando que a absorção desses cátions pode ser governada mais pela atividade do potássio em solução que propriamente de cálcio e magnésio, fato que vem 
comprovar, também, que, em termos de absorção de bases trocáveis pela planta, o equilíbrio de cátions em solução pode ser mais importante que a própria concentração do nutriente em solução (Bull et al., 1998). Primavesi \& Malavolta (1980) verificaram que a omissão de potássio resultou em aumento nos teores de $\mathrm{Mg}$ nas folhas do maracujazeiro mas para Malavolta (1981), altas concentrações de K e Mg reduzem a absorção de Ca.

A adição de potássio pela água de irrigação reduziu linearmente a acumulação de boro nas plantas, uma vez que os maiores teores foliares foram determinados nos tratamentos sem o elemento (Figura 1D). Quanto aos efeitos da irrigação, os maiores valores de concentração de boro nas folhas também o foram nos tratamentos que não receberam potássio (0,00 kg de $\mathrm{K}_{2} \mathrm{O}$ por planta), destacando-se os valores de 24,45 e 25,33 $\mathrm{mg} \mathrm{kg}^{-1}$, nos tratamentos com os menores níveis de irrigação, 0,25 e 0,50 L, respectivamente; esta situação diverge de Menzel et al. (1986), ao constatarem efeitos significativos de níveis de umidade no solo na concentração de boro em folhas do maracujazeiro.

Foi notória a redução nos teores de boro nas folhas do maracujazeiro amarelo com o aumento das doses de potássio aplicadas ao solo por fertirrigação, o que está de acordo com Reeve \& Shive (1944) apud Primavesi \& Malavolta (1980) e Borges et al. (2002), ao constatarem deficiência de boro em meio com alta concentração de potássio divergindo; no entanto, de Primavesi \& Malavolta (1980) e Carvalho et al. (2001) que não notaram efeitos da falta de potássio na absorção de boro pelo maracujazeiro amarelo.

Haag et al. (1973) encontraram teores de boro na folha do maracujazeiro amarelo entre 25,6 e $67,8 \mathrm{mg} \mathrm{kg}^{-1}$ e sugerem, adequados à cultura, valores médios entre 39 e $47 \mathrm{mg} \mathrm{kg}^{-1}$. Variação nesta amplitude foi obtida também por Primavesi \& Malavolta (1980) em cultivo sob solução nutritiva; já de acordo com Malavolta et al. (1997) teores de boro variando de 40 a $50 \mathrm{mg} \mathrm{kg}^{-1}$ são mais adequados ao maracujazeiro amarelo.

Assim, de acordo com Malavolta et al. (1997) os resultados obtidos neste trabalho são inferiores aos exigidos pela cultura, evidenciando que, por ocasião da amostragem, o maracujazeiro estava deficiente em boro, o que pode estar relacionado com as diferentes épocas de amostragem e exportação deste elemento para os frutos, uma vez que, na zona de concentração das raízes, os teores de boro variaram de médio a alto, e as amostras de folhas foram colhidas em plena fase de colheita, de acordo com Raij (1991).

Os níveis de irrigação não influenciaram significativamente os teores de manganês nas folhas do maracujazeiro; as variações nos teores do micronutriente devido aos níveis de irrigação, não foram expressivas, porém a concentração de Mn obtida com a combinação $\mathrm{L}_{4} \mathrm{~K}_{3}\left(140,75 \mathrm{mg} \mathrm{kg}^{-1}\right)$ foi bem inferior aos valores de $286,51,268,10$ e $293,70 \mathrm{mg} \mathrm{kg}^{-1}$ obtidos nos tratamentos $\mathrm{L}_{1} \mathrm{~K}_{3}, \mathrm{~L}_{2} \mathrm{~K}_{3}$ e $\mathrm{L}_{3} \mathrm{~K}_{3}$, respectivamente.

A análise de variância revelou efeitos significativos $(\mathrm{P}<0,01)$ dos níveis de potássio sobre os teores de manganês nas folhas do maracujazeiro amarelo, em que os resultados se adequaram significativamente $(\mathrm{P}<0,01)$ ao modelo polinomial quadrático (Figura 1E), constatando que o teor de manganês cresce com o aumento da dose de potássio aplicada por fertirrigação, até $0,46 \mathrm{~kg}$ de $\mathrm{K}_{2} \mathrm{O}$ planta $^{-1}$ reduzindo, posteriormente, sempre que esta aumenta, o que está de acordo com Malavolta (1981), Primavesi \& Malavolta (1980) e Mesquita et al. (2006), ao constatarem que o aumento do potássio no solo inibiu os teores de $\mathrm{Mn}$ acumulados nas folhas do maracujazeiro amarelo.

Os valores mínimos de 133,15, médios de 230,46 e máximos de 239,63 $\mathrm{mg} \mathrm{kg}^{-1}$ de manganês nas folhas obtidos neste trabalho, foram superiores à variação de 45,1 a $174 \mathrm{mg} \mathrm{kg}^{-1}$, registrados por Aguirre (1977), Menzel et al. (1986), Primavesi \& Malavolta (1980) e Menzel et al. (1991), e inferiores aos obtidos por Haag et al. (1973) e Menzel \& Simpson (1988), cujos teores oscilaram de 433 a $604 \mathrm{mg} \mathrm{kg}^{-1}$ e 447 a $737 \mathrm{mg} \mathrm{kg}^{-1}$, respectivamente.

\section{CONCLUSÕES}

1. Os teores de nutriente nas folhas do maracujazeiro amarelo não são influenciados pelos níveis de irrigação nem pela interação níveis de irrigação x níveis de potássio.

2. Os teores de $\mathrm{K}$ nas folhas crescem com o aumento dos níveis de potássio aplicados.

3. Maiores absorções de Ca e Mg e B pelo maracujazeiro ocorrem na ausência ou com pequenas doses de $\mathrm{K}$ aplicados.

4. A acumulação foliar de Mn cresce com o aumento da dose de potássio até $0,46 \mathrm{~kg}$ de $\mathrm{K}_{2} \mathrm{O}$ planta ${ }^{-1}$.

\section{LITERATURA CITADA}

Aguirre, A. C. P. Nutrição mineral do maracujá amarelo (Passiflora edulis Sims f. flavicarpa). Piracicaba: ESALQ/USP. 1977. 116p. Dissertação Mestrado

Araújo, R. C.; Bruckner, C. H.; Martinez, H. E. P.; Salomão, L. C. C.; Alvarez, V. H.; Dias, J. M. M.; Pereira, W. E.; Sousa, J. A. Crescimento e produção de maracujazeiro - amarelo em resposta à nutrição potássica. Revista Brasileira de Fruticultura, Jaboticabal, v.27, n.1, p.128-131, 2005.

Baumgartner, J. G.; Lourenço, R. S.; Malavolta, E. Estudos sobre a nutrição mineral e adubação do maracujazeiro (Passiflora edulis Sims f. flavicarpa Deg.) V. adubação mineral. Científica, São Paulo. v.6, n.3, p.361-7, 1978.

Borges, A. L.; Caldas, R. C.; Lima, A. de A.; Almeida, I. E. de. Efeito das doses de NPK sobre os teores de nutrientes nas folhas e no solo, e na produtividade do maracujazeiro amarelo. Revista Brasileira de Fruticultura, Jaboticabal, v.24, n.1, p.208213, 2002.

Bull, L. T.; Villas Boas, R. L.; Nakagawa, J. Variações no balanço catiônico do solo induzidas pela adubação potássica e efeitos na cultura do alho vernalizado. Scientia Agrícola, Piracicaba, v.55, n.3. p.456-464. 1998.

Carvalho, A. J. C. de.; Martins, D. P.; Monnerat, P. H.; Silva, J. A. da. Teores de nutrientes foliares no maracujazeiro-amarelo associados à estação fenológica, adubação potássica e lâminas de irrigação. Revista Brasileira de Fruticultura, Jaboticabal, v.23, n.2, p.403-408, 2001. 
Carvalho, A. J. C.; Monnerat, P. H.; Martins, D. P.; Bernado, S. Silva, J. A. da. Teores foliares de nutrientes no maracujazeiro amarelo em função de adubação nitrogenada, irrigação e épocas de amostragem. Scientia Agrícola, Piracicaba, v.59, n.1, p.121-127, 2002.

Cavalcante, L. F.; Dias, T. J.; Gondim, S. C.; Cavalcante, I. H. L.; Alves, G. S.; Araújo, F. A. R. Desenvolvimento e produção do maracujazeiro IAC 273/277 + 275 em função do número de ramos principais por planta. Agropecuária Técnica, Areia, v.26, n.2, p.141-151. 2005.

Dias, T. J.; Cavalcante, L. F.; Godim, S. C.; Raposo, R. W. C; Cavalcante, Í. H. L.; Santos, G.D. dos. Composição foliar de macronutrientes em maracujazeiro-amarelo e fertilidade do solo em função do número de ramos laterais por planta. Anais do Curso de Pós-graduação em Manejo de Solo e Água, Areia, v. 26, p.81-97, 2004.

EMBRAPA - Empresa Brasileira de Pesquisa Agropecuária. Manual de método de analises de solo. 2.ed., rev, Rio de Janeiro: Embrapa-CNPS, 1997. 212p. Documentos, 1

Haag, H. P; Oliveira, G. D; Borduchi, A. S.; Sarruge, J. R. Absorção de nutrientes por duas variedades de maracujá. Anais da Escola Superior de Agricultura “Luiz de Queiroz”, v.30, p.267279, 1973.

IFA (Paris, França). World fertilizer use manual. Limburgerhaf: BASF Agricultural Research Station, 1992. 632p.

Kliemann, H. J; Campelo Júnior, J. H; Azevedo, J. A. de; Guilherme, M. R.: Gen, N. P. de C. Nutrição mineral e adubação do maracujazeiro. In: Haag, H. P., ed. Nutrição mineral e adubação de fruteiras tropicais. Campinas: Fundação Cargill, 1986. p.247-284.

Malavolta, E. Manual de química agrícola - adubos e adubações. 3.ed. São Paulo: Agronômica Ceres, 1981. 596p.

Malavolta, E; Vitti, G. C.; Oliveira, S. A. Avaliação do estado nutricional das plantas, princípios e aplicações. 2:ed. Piracicaba: Associação Brasileira para a Pesquisa do Potássio e do Fosfato, 1997. 281p.

Meletti, L. M. M. Maracujá: Produção e comercialização em São Paulo. Campinas: IAC, 26p. 1996. Boletim técnico, 158

Meletti, L. M. M.; Maia, M. L. Maracujá: produção e comercialização. Campinas: IAC, 1999. 64p. Boletim técnico, 181

Menzel, C. M.; Haydon, G. E.; Doogan, V. J.; Simpson, D. R. New standard leaf nutrient concentrations for passion fruit based on seasonal phenology and leaf composition. Journal of Horticultural Science, Ashford Kent, v.68, n.2, p.215-230, 1993.

Menzel, C. M.; Haydon, G. F.; Simpson, D. R. Effect of nitrogen on growth and flowering of passionfruit (Passiflora edulis Sins f. edulis x P. edulis f. flavicarpa) in sand culture. Journal of Horticultural Science, Ashford Kent, v.66, n.6, p.689-702, 1991.
Menzel, C. M.; Simpson, D. R. Effect of continuous shading on growth, flowering and nutrient uptake of passion fruit. Scientia Horticulturae, Amsterdam, v.35, p.77-88, 1988.

Menzel, C. M.; Simpson, D. R.; Dowling, A. J. Water relations in passion fruit: Effect of moisture stress on growth, flowering and nutrient uptake. Scientia Horticulturae, Amsterdam, v.29, p.239-349, 1986.

Mesquita, F. O.; Dantas, T. A. G.; Cavalcante, L. F.; Sousa, G. G.; Araújo, F. A. R.; Campos, V. B. Composição mineral do maracujazeiro-amarelo sob adubação potássica, biofertilizante e cobnertura do solo. In: Congresso Brasileiro de Fruticultura, 19, 2006, Cabo Frio. Palestras e Resumos... Cabo Frio: SBF, 2006. p. 527.

Prado, R. de M.; Braghirollp, L. L.; Natale, W.; Corrêa, M. C. de M.; Almeida, E. V. de. Aplicação de potássio no Estado nutricional e na produção de matéria seca de mudas de maracujazeiro amarelo. Revista Brasileira de Fruticultura. Jaboticabal, v.26, n.2, p.295-299, 2004.

Primavesi, A. C. P. A.; Malavolta, E. Estudos sobre a nutrição mineral do maracujá amarelo. VI. Efeitos dos macronutrientes no desenvolvimento e composição mineral das plantas. Anais da Escola Superior de Agricultura "Luiz de Queiroz”, v.37, n.2, p.609-630, 1980.

Quaggio, J. A.; Piza Júnior, C. de T. Nutrição mineral e adubação da cultura do maracujá. In: Ruggiero, C. (ed). Maracujá do plantio à colheita. Jaboticabal: FCAV/SBF. 1998. p.130-156.

Raij, B. van. Fertilidade do solo e adubação. Piracicaba: CERES/ POTAFOS, 1991. 343p.

Rizzi, L. C.; Rabello, L. R.; Morozini Filho, W.; Savazaki, E. T.; Kavati, R. Cultura do maracujá azedo. Campinas: CATI. 1998. 53p. Boletim técnico, 235

Ruggiero, C.; São José, A. R.; Volpe, C. A.; Oliveira, J. C. de; Durigan, J. F.; Baumgartner, J. G.; Silva, J. R. W.; Nakamura, K.; Ferreira, M. E.; Kavati, R.; Pereira, V. de P. Maracujá para exportação: Aspectos técnicos da produção. Embrapa-SPI, 1996. 64p. Publicações Técnicas FRUPEX, 19

Santos, G. D. Avaliação do maracujazeiro-amarelo sob biofertilizantes aplicados ao solo na forma líquida. Areia: UFPB. 2004. 74p. Dissertação Mestrado

Sousa, V. F. de. Níveis de irrigação e doses de potássio aplicados via fertirrigação por gotejamento no maracujazeiro amarelo (Passiflora edulis Sims. f. flavicarpa Deg). Piracicaba: ESALQ/USP, 2000. 178p. Tese Doutorado

Souza, J. S. I.; Meletti, L. M. M. Maracujá: Espécies, variedades, cultivo. Piracicaba: FEALQ, 1997. 179p.

Teixeira, C. G. Maracujá: Cultura, matéria prima, processamento e aspectos econômicos. Campinas: ITAL, 1998. 267p. Série Frutas Tropicais 